\title{
Modulation of SHBG binding to testosterone and estradiol by sex and morbid obesity
}

\author{
María del Mar Grasa1,4,5, José Gulfo', Núria Camps' ${ }^{1}$ Rosa Alcalá ${ }^{1}$, \\ Laura Monserrat', José María Moreno-Navarrete ${ }^{2,3,5}$, Francisco José Ortega ${ }^{2,3,5}$, \\ Montserrat Esteve 1,4,5, Xavier Remesar 1,4,5, José Antonio Fernández-López 1,4,5, \\ José Manuel Fernández-Real ${ }^{2,3,5}$ and Marià Alemany 1,4,5 \\ 1Department of Biochemistry and Molecular Biomedicine; Faculty of Biology, University of Barcelona, \\ Barcelona, Spain, '2University Hospital 'Dr. Josep Trueta', Girona, Spain, ${ }^{3}$ Girona Institute of Biomedical \\ Research, and Hospital of Girona 'Dr. Josep Trueta', Spain, ${ }^{4}$ Institute of Biomedicine, University of \\ Barcelona, Barcelona, Spain, and ${ }^{5} \mathrm{CIBER}$ Obesity and Nutrition, Barcelona/Girona, Spain
}

\author{
Correspondence \\ should be addressed \\ to M Alemany \\ Email \\ malemany@ub.edu
}

\section{Abstract}

Objective: Sex hormone-binding globulin (SHBG) binds and transports testosterone and estradiol in plasma. The possibility that SHBG is a mixture of transporting proteins has been postulated. We analyzed in parallel the effects of obesity status on the levels and binding capacity of circulating SHBG and their relationship with testosterone and estradiol.

Design: Anthropometric measures and plasma were obtained from apparently healthy young (i.e. $35 \pm 7$ years) premenopausal women $(n=32)$ and men $(n=30)$, with normal weight and obesity $\left(\mathrm{BMI}>30 \mathrm{~kg} / \mathrm{m}^{2}\right)$. Methods: SHBG protein (Western blot), as well as the plasma levels of testosterone, estradiol, cortisol and insulin (ELISA) were measured. Specific binding of estradiol and testosterone to plasma SHBG was analyzed using tritiumlabeled hormones.

Results: Significant differences in SHBG were observed within the obesity status and gender, with discordant patterns of change in testosterone and estradiol. In men, testosterone occupied most of the binding sites. Estrogen binding was much lower in all subjects. Lower SHBG of morbidly obese (BMI $>40 \mathrm{~kg} / \mathrm{m}^{2}$ ) subjects affected testosterone but not estradiol. The ratio of binding sites to SHBG protein levels was constant for testosterone, but not for estradiol. The influence of gender was maximal in morbid obesity, with men showing the highest binding/SHBG ratios.

Conclusions: The results reported here are compatible with SHBG being a mixture of at least two functionally different hormone-binding globulins, being affected by obesity and gender and showing different structure, affinities for testosterone and estradiol and also different immunoreactivity.

\section{Introduction}

Hormone-binding globulins are serpins, whose main role is to specifically bind and transport steroid and thyroid hormones in plasma. Sex hormone-binding globulin (SHBG) essentially binds/transports testosterone and estradiol (1). The finding of its possible use as marker of a number of metabolic $(2,3)$ or psychological (4) disorders has contributed to enhance the study of SHBG's role in the control of gene expression (5) and sex hormone levels

www.eje-online.org DOI: 10.1530/EJE-16-0834 (c) 2017 European Society of Endocrinology Printed in Great Britain
European Journal of Endocrinology

(2017) 176, 393-404
$(6,7)$, as well as its more than probable implication in metabolic syndrome (MS) (8).

The function of SHBG is far from being fully understood. In fact, although it binds the hormone ligands in a high-affinity specific way, SHBG levels in plasma are low in comparison with albumin and other plasma proteins. The latter bind non-specifically these same hormones with high capacity and low affinity. The 
equilibrium of free hormone levels, thus, is dependent not only solely on SHBG-binding ability or levels but also on its interaction with tissues and their complex and variably modulated compartmentation (9). The absence of SHBG in rodents, in contrast with CBG, present in them and in humans, may hint at additional functions for this serpin, but the presence of a specific testosterone-binding protein in rodent testicles (10), with a marked structural and gene parallelism with SHBG $(11,12)$ suggests that at least for this organ, a testosterone-binding protein is required.

The high-affinity binding of sex hormones to SHBG competes with cell receptors, altering its direct availability, which prompts the question whether the main role of SHBG is to transport the hormones or retain them to modulate their binding to cell membranes, including the specific binding of SHBG itself (13). This sequestering role has been postulated for tissues, where membrane-related hormone-binding globulins may act barrier-like to limit or control the access of active hormones to cells, as is the case for CBG (14). However, hormone-binding globulins are required as vector for transfer of hormones to cell ligands (15), to elicit effects on gene expression and the activation of other cell functions $(16,17)$.

SHBG is a glycoprotein (18), which appears in plasma as a dimer, containing two subunits, each one having a site able to bind testosterone, dihydrotestosterone or estradiol (19). The affinity for testosterone has been found to be higher than that for estradiol (20) in line with the function of the precursor testosterone-binding protein of rodents compared with that of plasma and testicles in rabbits (21). In human plasma, SHBG has been found in several forms of variable molecular weight, distributed in markedly different proportions $(22,23)$; however, they shared the peptide size and immunoreacting properties, albeit only partially $(22,24)$. The difference in size has been largely attributed to the varying proportion of oligosaccharide chains $(23,25)$. SHBG hormone-binding affinity can be changed by molecular modulation of the serpin structure, such as localized proteolysis (26) and proteolytic cleavage resulting in increased free hormone levels because of loss of affinity of the protein to its ligand (2). Other possible modifications of SHBG structure/binding are the formation of O- or N-glycans $(27,28)$. An important factor of variability/regulation is the complex control $(29,30)$ of the expression of the single SHBG gene described (12), able to generate different products (12). In addition, a number of genetic variants, showing different hormone-binding affinities, has been described $(31,32)$.
Plasma concentrations of free testosterone and estradiol are related to the levels of SHBG (33). Sex affects markedly the levels $(34,35)$ and function of SHBG, essentially altering the levels of testosterone (36). The important modulatory effects of estradiol and testosterone, confronting (or allied to) the effects of glucocorticoids $(37)$ and insulin $(38,39)$ have been clearly established to show sex-related differences (40, 41) especially under conditions of predominance of insulin resistance and glucocorticoid action as in MS $(37,41)$. SHBG has been associated to the risk of MS in men $(38,42)$, independently of testosterone levels (43), whereas the relation of this syndrome with total or free testosterone is, at most, weak $(44,45)$. Women with MS showed increased testosterone and lower SHBG independently of menopausal status (46).

Obesity is known to lead to insulin resistance (47), increase the risk of MS (48) and it is also associated with hypercortisolism (49), hypoandrogenism (42) and increased estrogens (50). In the present study, we studied whether SHBG function is modified by obesity status. The key question was to determine whether the changes that SHBG experiences with obesity are a direct consequence of the existence of different molecular species of this protein.

\section{Subjects and methods}

\section{Study population}

A sample of 62 subjects (32 of them women) of Caucasian origin, aged between 18 and 50 years (i.e. $35 \pm 7$ years) and including patients at the extremes of the weight continuum (16 participants with severe obesity (BMI $\geq 40 \mathrm{~kg} / \mathrm{m}^{2}$ ), 19 obese subjects and 28 ageand gender-matched healthy-weight controls (BMI $\left.<25 \mathrm{~kg} / \mathrm{m}^{2}\right)$ ) were enrolled for hormonal and circulating assessment of target proteins. Six groups of subjects were established and studied comparatively: (A) women with normal weight: BMI $<25 \mathrm{~kg} / \mathrm{m}^{2}$; (B) obese women: $30 \leq \mathrm{BMI}<40 \mathrm{~kg} / \mathrm{m}^{2}$; (C) morbidly obese women: BMI $\geq 40 \mathrm{~kg} / \mathrm{m}^{2}$; (D) men with normal weight: BMI $<25 \mathrm{~kg} / \mathrm{m}^{2}$; (E) obese men: $30 \leq \mathrm{BMI}<40 \mathrm{~kg} / \mathrm{m}^{2}$ and (F) morbidly obese men: BMI $\geq 40 \mathrm{~kg} / \mathrm{m}^{2}$. Inclusion criteria, in addition to the BMI ranges described above, were the absence of any systemic disease and the absence of any infections in the previous month. None of the subjects was taking medication (including glucocorticoids or estrogens) or showed evidence of metabolic disease other than obesity. All subjects reported that their 
body weight had been stable for at least 3 months before the study. Liver disease and thyroid dysfunction were specifically excluded by biochemical workup. All women had regular menstrual cycles and were studied on days 3-8 of the cycle. All participants were in apparently good health were and free of cardiovascular pathologies, clinically defined diabetes or hypertension.

The protocol was approved by the Hospital Ethics Committee, and informed consent was obtained from each subject.

Baseline studies included a standardized questionnaire, physical examination and common laboratory tests. Height and weight were measured with the participant in light clothing and barefoot. BMI was calculated, and blood pressure was measured in the supine position, using a sphygmomanometer of appropriate cuff size; the first and fifth phases were recorded.

\section{Analytical procedures}

Blood samples were collected, after a 12-h fast, into blood collection tubes with a serum separator. After $15 \mathrm{~min}$, tubes were centrifuged at $1500 \times \boldsymbol{g}$ for $10 \mathrm{~min}$ at room temperature. The serum glucose was measured in duplicate by a glucose oxidase/ peroxidase method (Glucose Analyzer 2; Beckman Coulter, Inc., Brea, CA, USA). The coefficient of variation was $1.9 \%$. Serum insulin levels were measured in duplicate by monoclonal immunoradiometric assay (Medgenix Diagnostics, Fleunes, Belgium). The lowest limit of detection was $28 \mathrm{pM}$. The intra-assay coefficient of variation was $5.2 \%$ at a concentration $70 \mathrm{pM}$ and $3.4 \%$ at a $900 \mathrm{pM}$. The inter-assay coefficients of variation were $6.9 \%$ and $4.5 \%$ at $100 \mathrm{pM}$ and $620 \mathrm{pM}$ respectively. Blood glycosylated hemoglobin (HbA1c) proportions were analyzed by high-pressure liquid chromatography (Merck Diagnostics, Darmstadt, Germany), with coefficients of variation below $4 \%$. The range for HbA1c in glucosetolerant subjects was $3.8-5.4 \%$. Total serum cholesterol was measured through the reaction of cholesterol esterase/oxidase/ peroxidase, using a BM/Hitachi 747 analyzer (Hitachi). HDL cholesterol was quantified after precipitation with polyethylene glycol at room temperature. Total serum triacylglycerols were measured through lipolysis and the analysis of glycerol evolved with glycerol-phosphate-oxidase/peroxidase. Whole blood hemoglobin levels (containing EDTA) were determined by a routine laboratory method (Coulter Electronics, Hialeah, FL, USA).

Solid-phase enzyme-linked immunosorbent assays (ELISA) based on the sandwich principle were used for the quantitative determination of plasma estradiol (kit EIA-2693) and testosterone (kit EIA-1559, both from DRG International; Marburg, Germany). Plasma cortisol was determined by microparticle enzyme immunoassay (IMX system, Abbott Laboratories, North Chicago, IL, USA), with intra- and inter-assay coefficients of variation less than $8 \%(51)$.

\section{Western blot of SHBG}

Plasma SHBG was estimated by Western blot using monoclonal anti-human SHBG (LS-C198189; LifeSpan Biosciences, Seattle, WA, USA) as primary antibody,

Table 1 Basic characteristics of the human subject groups used in the present study. The values are presented as mean \pm S.E.M. for each group. Statistical analysis of the differences between groups (2-way ANOVA) was carried out for the parameters 'sex', 'obesity' and their interaction.

\begin{tabular}{|c|c|c|c|c|c|c|c|c|c|}
\hline \multirow[b]{2}{*}{ Parameters } & \multicolumn{3}{|c|}{ Women } & \multicolumn{3}{|c|}{ Men } & \multicolumn{3}{|c|}{$\boldsymbol{P}$} \\
\hline & $\begin{array}{l}\text { Normal } \\
\text { weight }\end{array}$ & Obese & $\begin{array}{l}\text { Morbid } \\
\text { obese }\end{array}$ & $\begin{array}{l}\text { Normal } \\
\text { weight }\end{array}$ & Obese & $\begin{array}{l}\text { Morbid } \\
\text { obese }\end{array}$ & Sex & Obesity & Interaction \\
\hline$n$ & 14 & 10 & 8 & 13 & 9 & 8 & - & - & - \\
\hline Age, years & $36 \pm 2$ & $32 \pm 2$ & $32 \pm 1$ & $35 \pm 2$ & $41 \pm 3$ & $36 \pm 2$ & NS & NS & NS \\
\hline Weight, Kg & $61 \pm 1$ & $90 \pm 3$ & $121 \pm 5$ & $69 \pm 2$ & $101 \pm 4$ & $141 \pm 10$ & 0.0003 & $<0.0001$ & NS \\
\hline Height, m & $1.66 \pm 0.01$ & $1.64 \pm 0.02$ & $1.64 \pm 0.02$ & $1.74 \pm 0.02$ & $1.75 \pm 0.03$ & $1.76 \pm 0.03$ & $<0.0001$ & NS & NS \\
\hline $\mathrm{BMI}, \mathrm{Kg} / \mathrm{m}^{2}$ & $22.2 \pm 0.4$ & $33.4 \pm 1.0$ & $45.0 \pm 1.3$ & $22.7 \pm 0.3$ & $33.2 \pm 0.8$ & $45.4 \pm 2.2$ & NS & $<0.0001$ & NS \\
\hline Fasting plasma glucose, $\mathrm{mM}$ & $4.73 \pm 0.13$ & $4.76 \pm 0.12$ & $4.97 \pm 0.15$ & $5.32 \pm 0.15$ & $5.52 \pm 0.16$ & $6.13 \pm 0.21$ & $<0.0001$ & 0.0040 & NS \\
\hline $\mathrm{HbA}_{1 \mathrm{C}}, \%$ & $4.6 \pm 0.1$ & $4.9 \pm 0.1$ & $4.8 \pm 0.2$ & $4.8 \pm 0.1$ & $4.7 \pm 0.1$ & $5.4 \pm 0.2$ & NS & 0.0030 & 0.0270 \\
\hline HOMA-IR & $1.25 \pm 0.18$ & $2.43 \pm 0.36$ & $2.44 \pm 0.33$ & $1.40 \pm 0.23$ & $3.19 \pm 0.64$ & $3.96 \pm 0.42$ & 0.0094 & $<0.0001$ & NS \\
\hline Total plasma cholesterol, mM & $4.53 \pm 0.13$ & $5.00 \pm 0.29$ & $5.23 \pm 0.27$ & $5.23 \pm 0.21$ & $5.72 \pm 0.19$ & $5.39 \pm 0.41$ & 0.0128 & NS & NS \\
\hline HDL cholesterol, mM & $1.51 \pm 0.11$ & $1.30 \pm 0.08$ & $1.31 \pm 0.11$ & $1.32 \pm 0.11$ & $1.27 \pm 0.11$ & $1.04 \pm 0.08$ & NS & NS & NS \\
\hline LDL cholesterol, mM & $2.69 \pm 0.17$ & $3.09 \pm 0.24$ & $3.18 \pm 0.29$ & $3.45 \pm 0.21$ & $3.74 \pm 0.17$ & $3.39 \pm 0.42$ & 0.0107 & NS & NS \\
\hline Plasma triacylglycerols, $\mathrm{mM}$ & $0.779 \pm 0.054$ & $1.37 \pm 0.30$ & $1.66 \pm 0.19$ & $1.13 \pm 0.18$ & $1.67 \pm 0.33$ & $2.14 \pm 0.26$ & 0.0422 & 0.0002 & NS \\
\hline
\end{tabular}


and polyclonal against albumin (sc-46293, Santa Cruz Biotechnology, Santa Cruz, CA, USA) all of them raised against representative peptides. Proteins were run by SDS-PAGE (100 g/L resolving gel; $40 \mathrm{~g} / \mathrm{L}$ stacking gel). A protein MW marker scale (kaleidoscope, BioRad) was included in one of the wells. Samples of $1-2 \mu \mathrm{L}$ of plasma were used. Proteins were transferred to PVDFImmobilon (Millipore) membranes, which were visualized with Ponceau red. The membranes were blocked with TBST and $50 \mathrm{~g} / \mathrm{L}$ powdered skimmed milk, and then they were incubated at $4{ }^{\circ} \mathrm{C}$ overnight with the primary antibody diluted $1 / 2000$. The membranes were, then, washed four times and then exposed (for $1 \mathrm{~h}$ at room temperature), diluted $1 / 3000$, to the secondary antibody. After four washings, chemiluminescence was analyzed using ECL (Millipore) for $5 \mathrm{~min}$. Then, densitometric measurements were done using the Total-Lab program (Nonlinear USA, Durham, NC, USA). This Western blot is an adaptation of that previously developed by our group for the measurement of rat plasma CBG (52).

\section{Hormone-binding assays}

The basic procedure for hormone-binding assays was the same described by us previously for CBG (52). In short, samples of just-thawed plasma $(10 \mu \mathrm{L})$ were mixed with $1 \mathrm{~mL}$ of PBS (phosphate-buffered saline) $\mathrm{pH} 7.4$ containing $1 \mathrm{~g} / \mathrm{L}$ gelatin. Total binding was estimated using $0.150 \mathrm{~mL}$ of diluted supernatant, $0.025 \mathrm{~mL}$ of PBSgelatin and $0.025 \mathrm{~mL}$ of ${ }^{3} \mathrm{H}$-labeled estradiol (NET317: (2,4,6,7-3 H)-17 $\beta$-estradiol, Perkin-Elmer; specific activity $2.8 \mathrm{GBq} / \mathrm{mmol}$ ) or testosterone (NET370: $\left(1,2,6,7{ }^{3} \mathrm{H}\right.$ )testosterone, Perkin-Elmer, specific activity 2.6 GBq/ $\mathrm{mmol}$ ). Hormones' final concentration was $30 \mathrm{nM}$, with a specific radioactivity of $12 \mathrm{kBq} / \mathrm{nmol}$. Non-specific binding was estimated under the same conditions, but now adding $0.025 \mathrm{~mL}$ of non-labeled hormone in PBS-gelatin (final concentration $15 \mu \mathrm{M}$ ). In both cases, the tubes were incubated under gentle shaking for $20 \mathrm{~min}$ at $37^{\circ} \mathrm{C}$ followed by $2 \mathrm{~h}$ at $4^{\circ} \mathrm{C}$. Then, $0.200 \mathrm{~mL}$ of chilled dextran-charcoal PBS-gelatin buffer was added, and the tubes were vortexed and kept $10 \mathrm{~min}$ in ice. Finally, the tubes were centrifuged $10 \mathrm{~min}$ at $4^{\circ} \mathrm{C}$

Table 2 Hormone levels in serum of women and men with normal weight, obese or morbidly obese.

\begin{tabular}{|c|c|c|c|c|c|c|c|}
\hline \multirow[b]{2}{*}{ Plasma hormone levels } & \multirow{2}{*}{$\begin{array}{l}\text { Normal } \\
\text { weight }\end{array}$} & \multirow[b]{2}{*}{ Obese } & \multirow{2}{*}{$\begin{array}{l}\text { Morbid } \\
\text { obese }\end{array}$} & \multirow{2}{*}{$\begin{array}{c}\text { 1-way Anova } \\
\text { P-obesity }\end{array}$} & \multicolumn{3}{|c|}{ 2-way ANOVA } \\
\hline & & & & & $P$-sex & P-obesity & $P$-interaction \\
\hline Estradiol, pM & & & & & NS & 0.0043 & NS \\
\hline Women & $162 \pm 29$ & $173 \pm 25$ & $256 \pm 48$ & NS & & & \\
\hline Men & $134 \pm 16^{A}$ & $124 \pm 13^{A}$ & $215 \pm 22^{B}$ & 0.0044 & & & \\
\hline Testosterone, nM & & & & & $<0.0001$ & 0.0040 & 0.0002 \\
\hline Women & $1.19 \pm 0.18^{A}$ & $1.59 \pm 0.23^{\mathrm{AB}}$ & $2.31 \pm 0.36^{B}$ & 0.0125 & & & \\
\hline Men & $19.6 \pm 1.4^{\mathrm{A}}$ & $17.4 \pm 1.8^{\mathrm{A}}$ & $11.1 \pm 1.1^{\mathrm{B}}$ & 0.0020 & & & \\
\hline Cortisol, nM & & & & & NS & NS & NS \\
\hline Women & $407 \pm 38$ & $374 \pm 64$ & $277 \pm 64$ & NS & & & \\
\hline Men & $354 \pm 27$ & $382 \pm 34$ & $333 \pm 74$ & NS & & & \\
\hline Insulin, pM & & & & & NS & $<0.0001$ & NS \\
\hline Women & $42.2 \pm 5.4^{\mathrm{A}}$ & $82.5 \pm 12.1^{\mathrm{B}}$ & $77.4 \pm 10.9^{B}$ & 0.0034 & & & \\
\hline Men & $41.4 \pm 6.2^{\mathrm{A}}$ & $93.1 \pm 17.7^{B}$ & $103 \pm 10^{B}$ & 0.0004 & & & \\
\hline Testosterone/estradiol ratio & & & & & $<0.0001$ & 0.0078 & 0.0046 \\
\hline Women & $6.73 \pm 1.10^{\mathrm{A}}$ & $8.19 \pm 0.80^{A B}$ & $10.3 \pm 1.4^{\mathrm{B}}$ & NS & & & \\
\hline Men & $176 \pm 27^{A}$ & $155 \pm 19^{A}$ & $57.9 \pm 11.5^{B}$ & 0.0084 & & & \\
\hline Cortisol/testosterone ratio & & & & & $<0.0001$ & 0.0063 & 0.0045 \\
\hline Women & $441 \pm 65^{A}$ & $277 \pm 59^{A B}$ & $136 \pm 37^{B}$ & 0.0074 & & & \\
\hline Men & $19.1 \pm 2.1$ & $23.0 \pm 2.3$ & $24.2 \pm 5.4$ & NS & & & \\
\hline Cortisol/estradiol ratio, $\times 10^{-3}$ & & & & & NS & 0.0087 & NS \\
\hline Women & $3.23 \pm 0.67$ & $2.27 \pm 0.53$ & $1.49 \pm 0.61$ & NS & & & \\
\hline Men & $3.16 \pm 0.47^{A}$ & $3.25 \pm 0.40^{A}$ & $1.47 \pm 0.33^{B}$ & 0.0280 & & & \\
\hline Estradiol/insulin ratio & & & & & NS & NS & NS \\
\hline Women & $3.66 \pm 0.68$ & $4.43 \pm 1.50$ & $3.82 \pm 0.88$ & NS & & & \\
\hline Men & $4.49 \pm 0.98^{\mathrm{A}}$ & $1.54 \pm 0.20^{B}$ & $2.26 \pm 0.39^{A B}$ & NS & & & \\
\hline Testosterone/insulin ratio & & & & & $<0.0001$ & 0.0006 & 0.0005 \\
\hline Women & $31.5 \pm 7.2$ & $33.6 \pm 12.6$ & $33.6 \pm 6.2$ & NS & & & \\
\hline Men & $681 \pm 142^{\mathrm{A}}$ & $232 \pm 32^{\mathrm{B}}$ & $112 \pm 13^{B}$ & 0.0020 & & & \\
\hline
\end{tabular}



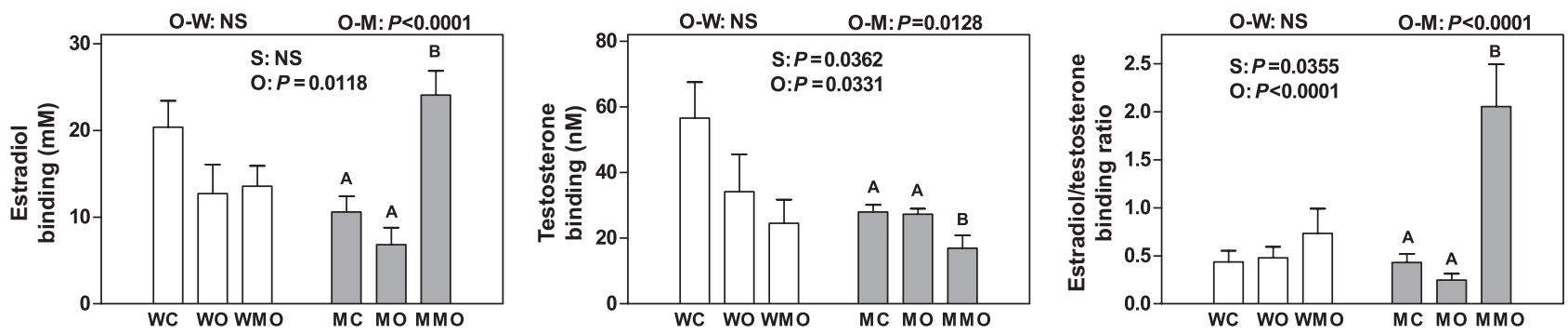

\section{Figure 1}

Estradiol and testosterone binding, as well as their ratio, for women and men of normal weight, obese and morbidly obese. The data are the mean \pm S.E.M. for each group. White bars represent women, gray bars represent men; WC, women of normal weight; WO, women obese; WMO, women morbidly obese; MC, men of normal weight; MO, men obese; MMO, men morbidly obese. Statistical analysis of the differences between groups: two-way ANOVA, (data within the Figure) was carried out for the parameters 'sex' (S) and 'obesity' (O). NS represents $P$ values higher than 0.050 . One-way ANOVA for obesity in each sex group (data on top of the Figure) O-W factor 'obesity' in women; O-M factor 'obesity' in men. Post-hoc Duncan test for one-way ANOVAs (obesity): different letters over the columns indicate a significant $(P<0.05)$ difference between them; the absence of letters reflects the absence of significant differences between the groups.

and $2000 \times \boldsymbol{g}$. Aliquots of the supernatants were used to measure the radioactivity bound to protein through liquid scintillation counting.

\section{Statistical methods}

Statistical comparisons were done using twoway ANOVA analyses (sex and obesity), with the Statgraphics Centurion XVI program package (Statpoint Technologies, Warrengton, VA, USA). Correlations were determined using the Prism 5 package (GraphPad Software Inc). Before statistical analysis, normal distribution and homogeneity of the variables were tested. Levels of statistical significance were set at $P<0.050$.

\section{Results}

Table 1 shows the basic plasma anthropometric and metabolic values of the six experimental groups. As expected, increased weight was concomitant with higher triacylglycerol levels in men and women, as well as with increased glycemia, insulin and HOMA-IR.

Table 2 presents the levels of plasma hormones and ratios between these levels. Estradiol concentrations showed no significant differences between women (in the follicular phase) and men. Morbid obesity was associated with increased estradiol levels, especially in men. As expected, testosterone showed marked sex-related differences, increasing with the severity of obesity in women and decreasing in men. No significant differences were observed regarding basal cortisol.

The ratio of testosterone to estradiol concentrations showed significant differences according to sex and obesity. Cortisol/testosterone ratios were significantly different in obese women, but not in obese men. In contrast, the cortisol/estradiol ratio was significantly different in obese men. The estradiol/insulin ratios were similar according to sex and obesity status; however, the testosterone/insulin ratios were clearly different for sex and BMI, being the effects of obesity a consequence of the 6-fold difference between morbidly obese men and controls.

Plasma SHBG-binding capacity for estradiol and testosterone is depicted in Figure 1. Estradiol binding showed no significant effect of sex, but obesity severity resulted in significant differences, solely attributable to males as the morbid obese had much higher and significantly different binding values than those obese or with normal weight. The pattern for testosterone binding was quite different, with significant effects of both sex and obesity, the latter attributable, again to the group of men, with morbidly obese subjects showing the lowest testosterone-binding values. These differences were magnified in the estradiol- vs testosterone-binding ratio. Both sex and obesity showed significant differences, with rather uniform ratios for all groups except for the morbidly obese men, with ratios several-fold higher than those in all other groups.

Figure 2 shows the levels of testosterone and estradiol as a proportion of SHBG-binding capacity. The only 

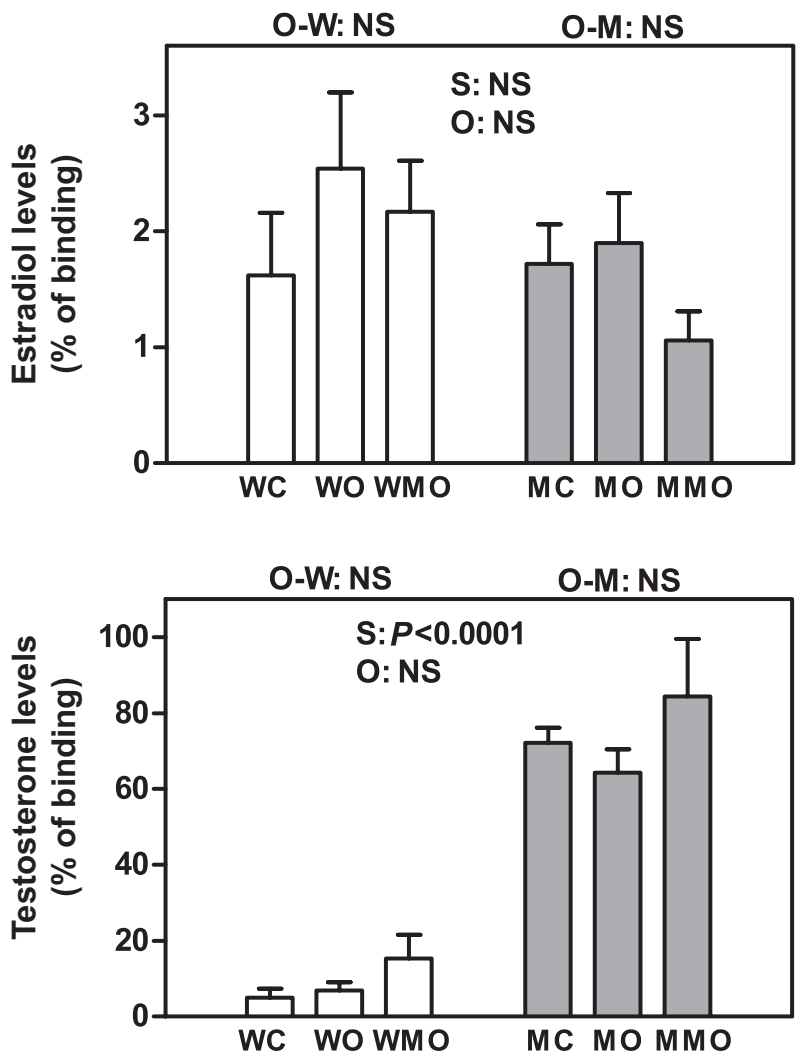

Figure 2

Relationship between the levels of estradiol or testosterone in plasma with respect to the binding ability of this same plasma, expressed as percentages. Figure conventions are the same as in Figure 1.

significant differences observed were for sex in the case of testosterone as in men, the levels accounted for $60-80 \%$ of maximal binding capacity of SHBG against 5-20\% for women. These data contrast with the rather uniform $1-3 \%$ values for estradiol levels vs binding.

Figure 3 presents the amount of SHBG protein in plasma, determined through Western blot. Normalweight women had almost 2.5-fold higher levels of circulating SHBG than the corresponding group of men; these differences were observed again in the morbid obese groups, but with all values practically halved. These differences were statistically significant according to sex (lower values in men) and obesity status (decreasing values with increasing obesity).

When estradiol or testosterone binding were related to the amount of SHBG protein (Fig. 4), the resulting binding/Western blot ratios showed the actual capacity to bind the hormones with respect to the amount of protein present in plasma (i.e. the total binding capacity being

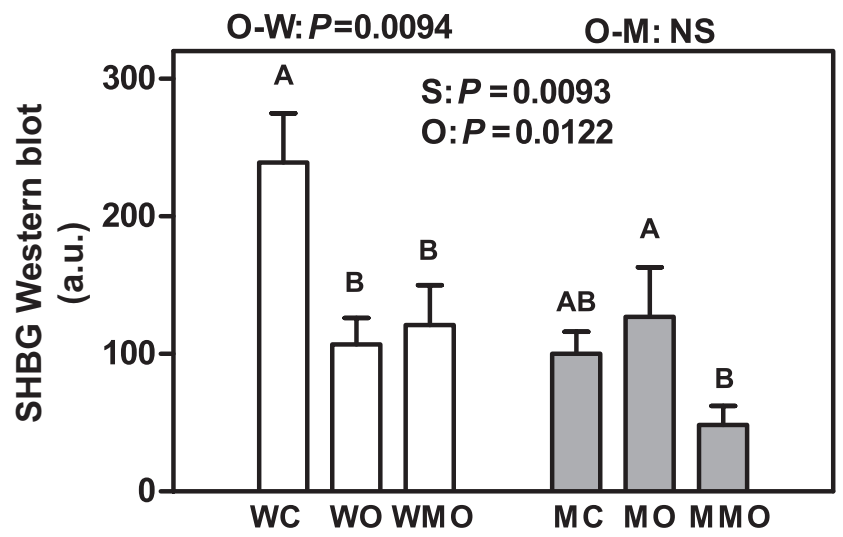

Figure 3

SHBG Western blot of women and men of normal weight, obese and morbidly obese. Figure conventions are the same as in Figure 1; a.u., arbitrary units (the MC mean value was attributed the arbitrary value of 100).

a correlate of the amount of functional protein present). This value is ancillary to the number (or affinity) of the binding sites per molecule of protein. Estradiol binding was markedly different among morbidly obese men. Thus, the ability to bind was a uniform correlate of the amount of SHBG available; however, in morbid obese men the ability to bind estradiol was much higher than that corresponding to the protein detected. In the case of testosterone, however, no significant differences for sex or obesity were found, with closely similar ratios of binding/ SHBG protein ratios for all groups.

\section{Discussion}

SHBG binds both testosterone and estradiol, but not with the same affinity $(1,53)$ and may be deeply modulated by sex $(34,35)$, insulin resistance $(38,39)$, proinflammatory cytokines (30) and other metabolic conditions or pathologies $(54,55)$. The physiologically functional (circulating) protein appears as a dimer (19), but the conditions used for Western blot do separate the individual monomers. The main consequence is the loss, under laboratory conditions, of possible fine regulation factors such as allosteric modulation (56) and the discrimination of dimers and heterodimers (29). However, the conditions used to determine the binding value (i.e. specific binding calculated after discounting unspecific binding) facilitate the direct comparison of the functionality of the SHBG-binding site (there is only one per glycoprotein monomer). That is, under the testing conditions, the affinity and capacity to bind a 

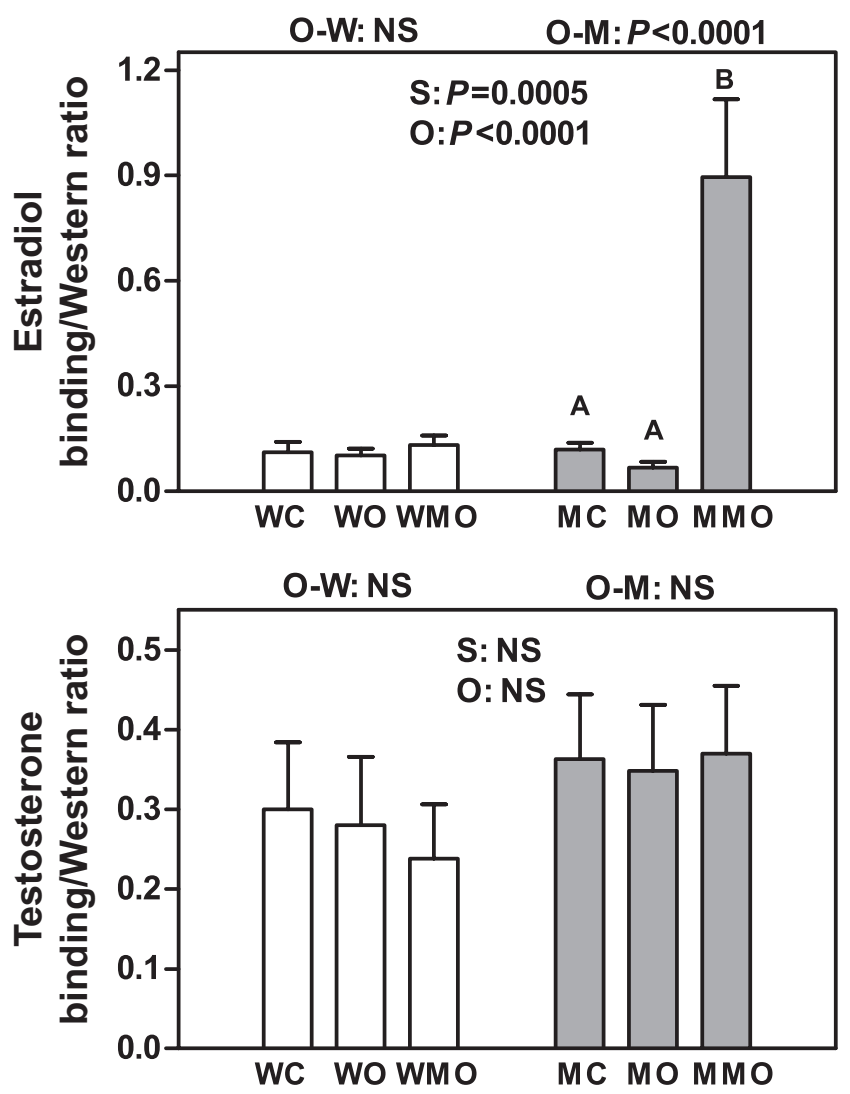

Figure 4

Ratios of estradiol and testosterone binding vs the SHBG Western blot data, for women and men of normal weight, obese and morbidly obese. Figure conventions are the same as in Figure 1.

given hormone (testosterone or estradiol) should remain unchanged. However, the binding/Western blot ratios, experimentally obtained, clearly were not. This result proves that in one of the groups of individuals (e.g. all the morbidly obese men), the SHBG molecule was structurally different.

The existence of varying molecular weight SHBG proteins (28), and the influence of the size of the monomers on binding has been already described (53). The changes in the SHBG molecule have been related to trimming of carbohydrate chains (23) and/or proteolytic shortening, in part attributed to regulatory serpin proteases such as kallikrein (26). However, changes were also observed in subjects with MS $(31,32,57,58)$, hepatic cirrhosis (54) or just population variability $(31,32)$. However, the marked change in SHBG ability to bind estradiol in the group of morbidly obese men described here is outstanding.

The binding/Western ratio for testosterone, was similar in all groups, as expected, including the morbidly obese men who also had the lowest levels of immunoreactive SHBG. The hormones' binding ratios did not show the expected uniform pattern, strongly deviated in morbid obesity instead; however, this deep change affected only men. Last, but not least, the relationship between the binding capacity of SHBG and the circulating hormone levels showed large differences for testosterone and estradiol (Fig. 2), in addition to the marked difference due to sex, largely a correlate of the higher circulating testosterone levels of men. In any case, the percentage of hormone levels vs binding in control women was in the range of $1.5 \%$, whereas that of testosterone was fivefold higher. These values were not within the expected range of work for SHBG to exert its transporting function under normal conditions; i.e., when the maximal proportion of binding sites bound to estradiol represent only a small fraction of the maximal-binding capacity of the protein, leaving no room for regulation. Consequently, the data on estradiol-related transporting capacity of SHBG did not match the currently accepted model of dual transport of androgen and estrogen for SHBG.

The results obtained do not support the assumption that SHBG is a protein indistinctly binding testosterone and estradiol as part of its physiological function. The data presented for males, even if only ascribed to the controls and non-extreme obesity (i.e. excluding the morbidly obese men), could not justify the transporting and regulatory function of SHBG for estradiol because of the sustained low level of binding site occupancy. This non-complying situation is magnified when compared with the SHBG-testosterone relationships as all and every one of the anomalies described for estradiol were fulfilled as expected. The phylogenetic closeness of SHBG to the testicular testosterone-binding protein (10) and the data presented here suggest that SHBG acts, essentially, as a testosterone-binding globulin. The fact that SHBG also binds estradiol must be put in perspective (59), especially given the marked differences in low circulating levels of estradiol compared with testosterone. Competence for a single binding site per monomer could not justify a functional role of the protein for estradiol, at least in males. Their much higher levels of testosterone than women compounded by the higher affinity of SHBG for the androgen, may result in negligible estrogen binding as regulatory mechanism in vivo (at least in males and non-ovulating women). The critical role of estradiol for bone (60), energy homeostasis (61) and reproductive system in both females and males (62) has been clearly established, requiring a finer regulation of estrogen in males, playing functions not fully coincident with those 
of females. The kinetics of binding of testosterone and estradiol did not match their expected function (which nevertheless is exerted successfully), especially when we consider that SHBG is also a carrier for hormones that bind to specific membrane sites to transfer their charge (63). In addition, most studies on SHBG function were centered on testosterone $(64,65)$. As a comparison, CBG is devoted not only to the control of cortisol (or corticosterone in rodents) but also binds progesterone and a number of other ligands (66); nevertheless, no role of CBG in transport or control of progesterone has been definitively proven. There is thus a clear parallelism between both serpins.

The apparent increase of estradiol-binding 'capacity' in morbidly obese men should be explained in terms of increased SHBG protein levels, but they were not. Furthermore, testosterone levels were unaffected, and the ratios for testosterone binding/Western blot were uniform for all men (and women) groups, a situation completely different to that of estradiol. A possible explanation of this inconsistency must lie on the existence of more than one type of SHBG protein, with at least one specifically binding estradiol, and the other testosterone. Thus, justifying the data observed in this study, despite testosterone alone responding as expected. This interpretation is coincident with previous reports that found different molecular species of SHBG binding either androgen or estradiol, but not both (in cirrhotic patients) (54), as well as the importance and common occurrence of SHBG alleles (22).

The extreme change in estradiol binding of morbidly obese men in comparison with the other groups could not be explained by the measured (Western) SHBG protein. However, testosterone complies under the same conditions. As estradiol levels were much lower, its plausible that an estradiol-binding globulin should be present in the morbidly obese men in lower levels than the 'current' or 'testosterone-prone' SHBG. This situation mimics that described for cirrhosis (54). The 'estradiolprone' SHBG, structurally close to 'testosterone-prone' SHBG should be formed by differential post-translational selective cleavage (26) of the SHBG transcript (22), thus preserving the similarity and similar (albeit probably not identical) immunoreactive properties (24) of both SHBG molecular species. The protein measured in this study had immunoreactive properties obviously dependent on the affinity and specificity of the antibody used, decanted toward one or other of the isoforms postulated, a situation parallel to that described by our group in rat CBG (52). Thus, in fact, we were not measuring SHBG (under the one molecule-for-all-hormones concept) but either a composite (with unknown proportions of both isoforms) or essentially one of these isoforms, that closer to bind/regulate testosterone. Anyway, a change in proportions of both forms of SHBG or changes in molar specific immunoreactivity may uncover the existence of more than one molecular species of circulating SHBG (54). The speculative ascription of different molecular species to the roles of transport and binding of estradiol and testosterone may help in understanding the complex conundrum of SHBG in relation with the control of sex hormone transport, function and their relationships under conditions of pathological alterations of energy homeostasis (30). Sex and age intensify the negative effects of MS, as observed in Koreans (67). Insulin is known to modulate the levels of testosterone through SHBG (30, $68,69)$, but what about estradiol? Binding of estradiol or testosterone to SHBG monomers (and probably dimers) changes their shape (53), thus affecting the conditions of binding to the cell membrane SHBG receptor sites.

An additional clue to the importance of the antagonistic gender-related function of cortisol and testosterone (37) can be directly derived from the analysis of their concentration ratios, markedly decreased with obesity in women and less affected in men. These differences are difficult to explain with the assumption of a unique SHBG regulating both testosterone and estradiol as the cortisol/estradiol concentration ratios were affected by obesity but not by sex. A similar picture can be drawn from the ratios of both sex hormones vs insulin: no effects were observed for estradiol, but men (albeit not women) showed marked effects of obesity, depending on its severity. These data hint at a much more significant (and gender-related) implication of testosterone in obesity (70). This is not only in agreement with the sexrelated incidence of the development of MS with age (71) but also with the known relationship of SHBG (probably the isoform controlling testosterone availability) and the incidence of MS $(58,72)$ and the development of gender-related (73) increased cardiovascular risk. These effects may be largely independent of the protective anti-inflammatory effect of estrogen (74). The lack of clear discrimination of SHBGs and their separate control of estrogen and androgen has obscured the implication of testosterone (or the lack of it) in contrast with the surge of glucocorticoids in the development of cardiovascular risk in women and old men (75) in parallel to increased frailty (76). As the fall in testosterone levels, at least in men, tend to be related to age (69), and this occurs in parallel to a fall in SHBG levels (65), we can assume that the results obtained in the present study should be extended to a larger population, with a wide age range. The important 
Table 3 The SHBG dual hormone-binding conundrum. Summary of the available reasons and experimental data proving the unsustainability of the SHBG dual role controlling/ transporting estradiol and testosterone.

Current accepted knowledge: a unique SHBG binds, transports and regulates the levels and availability of $T$ and $E 2$

Already known data that do not support the 'single SHBG' current theory

- $M$ and $W$ show different (and varying) levels of T and E2 with similar SHBG protein concentrations

- Widely different T and E2 levels in plasma apparently do not compete or interfere on SHBG function despite using a single binding site for which they compete as ligands

- Different SHBG forms have been found in humans with structural and binding affinity differences for $\mathrm{T}$ and E2

- Many animals do not have SHBG, but most possess non-circulating T-binding proteins; i.e. $T$ may be regulated independently of E2. In any case, T and E2 levels are regulated in plasma despite the eventual absence of SHBG Additional proof, presented here, against the 'single SHBG' current theory

- Circulating E2 (lower than T) at most may cover 3\% of the potential binding sites of concurrent plasma SHBG, which is not compatible with T occupying $65-90 \%$ of the sites. These data are not compatible with a regulation role of SHBG for E2

- Obesity affects T (but not E2) binding. This is incompatible with both hormones binding (competing) for the same SHBG-binding site if the protein remains unchanged

- The ratio of hormone binding vs protein level (Western blot) should be constant unless the protein affinity is changed (by changing the protein itself). The ratio for $\mathrm{T}$ is unaltered by sex and obesity, but that for E2 is affected by both

The conclusions are far reaching:

- Cannot be explained by the single type of SHBG, which brings us to assume that, at least there are two SHBGs, one regulating $T$ and the other for $E 2$

- Most of the methods used for the measurement of SHBG rely on their immunoreactivity, but they may detect/ measure a T- or E2-prone SHBG molecular species of a mixture of both in different proportions

- Consequently, there are no reliable methods for SHBG measurement available, in the sense that SHBG levels could not be related to a specific protein carrying out a specific function. This, largely invalidates many studies on SHBG function

- Specific discriminative methods for the SHBGs may help clarify the intuited role of estrogens and androgens on metabolic syndrome-related pathologic states

E2, estradiol; T, testosterone.

amount of data available on the dynamics of testosterone action and protein deposition (77) in conjunction with the main anabolic hormone, insulin, countered by corticosteroids (37) show that testosterone is a critical factor in the aging process (78). The discriminating role of the postulated dual SHBGs may help understand better the gender-related process of aging by establishing a clear mechanism of regulation of the plasma kinetics and transport of testosterone, but will also allow a deeper study of estrogens without interference.

In conclusion, our data point to SHBG as a globulin mainly centered in the control of testosterone levels, with estradiol regulation taking a markedly second place, or, simply, estradiol being controlled by a different SHBG variant. These data confirm the existence of different SHBG molecular species to discriminately bind estradiol and testosterone, previously reported in cirrhotic subjects (54). The sex-related differences in the relationships of binding vs levels of hormones and SHBG could not be explained by assuming that a single dimeric protein may experience the dramatic changes in affinity for testosterone and estradiol (differently for both, in fact) observed in women and men, and the marked differential effects of obesity on the ability of the same protein to bind testosterone and estradiol (Table 3).

Thus, we postulate that SHBG protein must be present in at least two different molecular species, or isoforms, to explain its differential function for both hormones, specially affected by sex and obesity. These conclusions suggest a much needed establishment of analytical procedures to identify these physiologically distinct forms of SHBG as the sole use of antibody-based measurements could not discriminate between them.

\section{Declaration of interest}

The authors declare that there is no conflict of interest that could be perceived as prejudicing the impartiality of the research reported.

\section{Funding}

This study was supported (Girona-based group) by the Spanish Ministry of Science and Innovation (FIS 2011-00214), Fondo Europeo de Desarrollo Regional (FEDER) and CIBER de la Fisiopatología de la Obesidad y la Nutrición (CIBERobn). The CIBERobn is an initiative from the Instituto de Salud Carlos III (ISCIII). The Barcelona-based group, in relation to the present study, did not receive any specific grant from any funding agency in the public, commercial or not-for-profit sector.

\section{Author contribution statement}

J M F-R, J M M-N and F J O selected the volunteers, obtained the samples and established the basal metabolic conditions of the subjects, including insulin. R A, N C, M E, J A F-L, M M G, J G and L M did the SHBG-related laboratory work. M E, J A F-L, M M G and $X$ R supervised the laboratory work, organized the results and did the final statistical analyses. M A conceived the study and wrote the paper. All senior authors participated in the discussion of the results and in shaping the final text. At the time when this investigation took place, R A, N C and L M were undergraduate students.

\section{Acknowledgements}

The authors thank the volunteers, who graciously allowed us to use their blood samples and data to carry out this experiment. 


\section{References}

1 Corvol PL, Chrambach A, Rodbard D \& Bardin CW. Physical properties and binding capacity of testosterone-estradiol-binding globulin in human plasma, determined by polyacrylamide gel electrophoresis. Journal of Biological Chemistry 1971246 3435-3443.

2 Veltman-Verhulst SM, van Haeften TW, Eijkemans MJC, de Valk HW, Fauser BCJM \& Goverde AJ. Sex hormone-binding globulin concentrations before conception as a predictor for gestational diabetes in women with polycystic ovary syndrome. Human Reproduction 201025 3123-3128. (doi:10.1093/humrep/deq272)

3 Al-Daghri NM, Khan N, Sabico S, Al-Attas OS, Alokail MS \& Kumar S. Gender-specific associations of serum sex hormone-binding globulin with features of metabolic syndrome in children. Diabetology and Metabolic Syndrome 20168 22. (doi:10.1186/s13098-016-0134-8)

4 Grasa MdM, Villarreal L, Granero R, Vilà R, Penelo E, Agüera Z, Jiménez-Murcia S, Romero MdM, Menchón JM, Remesar X et al. Purging behavior modulates the relationships of hormonal and behavioral parameters in women with eating disorders. Neuropsychobiology 201367 230-240. (doi:10.1159/000350473)

5 Chen H, Hewison M \& Adams JS. Control of estradiol-directed gene transactivation by an intracellular estrogen-binding protein and an estrogen response element-binding protein. Molecular Endocrinology 200822 559-569. (doi:10.1210/me.2007-0297)

6 Hammond GL. Molecular-properties of corticosteroid binding globulin and the sex-steroid binding-proteins. Endocrine Reviews 1990 11 65-79. (doi:10.1210/edrv-11-1-65)

7 Petra PH. The plasma sex steroid binding-protein (SBP or SHBG) - a critical-review of recent developments on the structure, molecularbiology and function. Journal of Steroid Biochemistry and Molecular Biology 199140 735-753. (doi:10.1016/0960-0760(91)90299-K)

8 Prescott J, Thompson DJ, Kraft P, Chanock SJ, Audley T, Brown J, Leyland J, Folkerd E, Doody D, Hankinson SE et al. Genome-wide association study of circulating estradiol, testosterone, and sex hormone-binding globulin in postmenopausal women. PLoS One 20127 e37815. (doi:10.1371/journal.pone.0037815)

9 Romero MM, Fernández-López JA, Remesar X \& Alemany M. Effect of sex and prior exposure to a cafeteria diet on the distribution of sex hormones between plasma and blood cells. PLoS One 20127 e34381. (doi:10.1371/journal.pone.0034381)

10 Ritzén EM, Nayfeh SN, French FS \& Dobbins MC. Demonstration of androgen-binding components in rat epididymis cytosol and comparison with binding components in prostate and other tissues. Endocrinology 197189 143-151. (doi:10.1210/endo-89-1-143)

11 Hagen FS, Arguelles C, Sui LM, Zhang W, Seidel PR, Conroy SC \& Petra PH. Mammalian expression of the human sex steroid-binding protein of plasma (SBP or SHBG) and testis (ABP) - characterization of the recombinant protein. FEBS Letters 1992299 23-27. (doi:10.1016/0014-5793(92)80091-T)

12 Hammond GL \& Bocchinfuso WP. Sex hormone-binding globulin: gene organization and structure function analyses. Hormone Research 199645 197-201. (doi:10.1159/000184787)

13 Rosner W, Hryb DJ, Khan MS, Nakhla AM \& Romas NA. Sex hormonebinding globulin - binding to cell-membranes and generation of a second messenger. Journal of Andrology 199213 101-106.

14 Grasa MM, Cabot C, Adán C, de Matteis R, Esteve M, Cinti S, FernándezLópez JA, Remesar X \& Alemany M. Corticosteroid-binding globulin synthesis and distribution in rat white adipose tissue. Molecular and Cellular Biochemistry 2001228 25-31. (doi:10.1023/A:1013304223967)

15 Rosner W, Hryb DJ, Khan MS, Nakhla AM \& Romas NA. Sex hormonebinding globulin mediates steroid hormone signal transduction at the plasma membrane. Journal of Steroid Biochemistry and Molecular Biology 199969 481-485. (doi:10.1016/S0960-0760(99)00070-9)

16 Roberts KP \& Zirkin BR. Androgen binding protein inhibition of androgen-dependent transcription explains the high minimal testosterone concentration required to maintain spermatogenesis in the rat. Endocrine Journal 19931 41-47.

17 Avvakumov GV, Cherkasov A, Muller YA \& Hammond GL. Structural analyses of sex hormone-binding globulin reveal novel ligands and function. Molecular and Cellular Endocrinology 2010316 13-23. (doi:10.1016/j.mce.2009.09.005)

18 Mickelson KE \& Pétra PH. Purification of the sex steroid binding protein from human serum. Biochemistry 197514 957-963. (doi:10.1021/bi00676a013)

19 Hammond GL \& Bocchinfuso WP. Sex hormone-binding globulin/ androgen-binding protein:steroid-binding and dimerization domains. Journal of Steroid Biochemistry and Molecular Biology 199553 543-552. (doi:10.1016/0960-0760(95)00110-L)

20 Mean F, Pellaton M \& Magrini G. Study of the binding of dihydrotestosterone, testosterone and oestradiol with sex hormone bunding globulin. Clinica Chimica Acta 197780 171-180. (doi:10.1016/0009-8981(77)90276-5)

21 Hansson V, Ritzen ME, French FS, Weddington SC \& Nayfeh SN. Testicular androgen-binding protein (ABP): comparison of ABP in rabbit testis and epididymis with a similar androgen-binding protein (TeBG) in rabbit serum. Molecular and Cellular Endocrinology 19753 1-20. (doi:10.1016/0303-7207(75)90028-3)

22 van Baelen H, Convents R, Cailleau J \& Heyns W. Genetic variation of human sex hormone-binding globulin: evidence for a bi-allelic gene. Journal of Clinical Endocrinology and Metabolism 199275 135-139. (doi:10.1210/jc.75.1.135)

23 Gershagen S, Henningsson K \& Fernlund P. Subunits of sex hormone binding globulin. Interindividual variation in size. Journal of Biological Chemistry 1987262 8430-8437.

24 Bukowski C, Grigg M \& Longcope C. Sex hormone-binding globulin concentration differences among common commercially available methods. Clinical Chemistry 200046 1415-1416.

25 Power S, Bocchinfuso WP, Pallesen M, Warmels-Rodenhiser S, Van Baelen H \& Hammond GL. Molecular analyses of a human sex hormone-binding globulin variant: evidence for an additional carbohydrate chain. Journal of Clinical Endocrinology and Metabolism 199275 1066-1070. (doi:10.1210/jc.75.4.1066)

26 Sanchez WY, de Veer SJ, Swedberg JE, Hong EJ, Reid JC, Walsh TP, Hooper JD, Hammond GL, Clements JA \& Harris JM. Selective cleavage of human sex hormone-binding globulin by kallikreinrelated peptidases and effects on androgen action in LNCaP prostate cancer cells. Endocrinology 2012153 3179-3189. (doi:10.1210/ en.2012-1011)

27 Bérubé D, Séralini GE, Gagné R \& Hammond GL. Localization of the human sex hormone-binding globulin gene SHBG to the short arm of chromosome 17 (17p12-p13). Cytogenetic and Genome Research 1990 54 65-67. (doi:10.1159/000132958)

28 Cousin P, Dechaud H, Grenot C, Lejeune H, Pugeat M, Baret C \& Brebant C. Human variant sex hormone-binding globulin (SHBG) with an additional carbohydrate chain has a reduced clearance rate in rabbit. Journal of Clinical Endocrinology and Metabolism $1998 \mathbf{8 3}$ 235-240. (doi:10.1210/jc.83.1.235)

29 Avvakumov GV, Muller YA \& Hammond GL. Steroid-binding specificity of human sex hormone-binding globulin is influenced by occupancy of a zinc-binding site. Journal of Biological Chemistry 2000 275 25920-25925. (doi:10.1074/jbc.M004484200)

30 Simó R, Sáez-López C, Barbosa-Desongles A, Hernández C \& Selva DM. Novel insights in SHBG regulation and clinical implications. Trends in Endocrinology and Metabolism 201526 376-383. (doi:10.1016/j.tem.2015.05.001)

31 Wu TS \& Hammond GL. Naturally occurring mutants inform SHBG structure and function. Molecular Endocrinology 201428 1026-1038. (doi:10.1210/me.2014-1058)

32 Vanbillemont G, Bogaert V, de Bacquer D, Lapauw B, Goemaere S, Toye K, van Steen K, Taes Y \& Kaufman JM. Polymorphisms of the SHBG gene contribute to the interindividual variation of sex 
steroid hormone blood levels in young, middle-aged and elderly men. Clinical Endocrinology 200970 303-310. (doi:10.1111/j.13652265.2008.03365.x)

33 de Ronde W, van der Schouw YT, Muller M, Grobbee DE, Gooren LJG, Pols HAP \& de Jong FH. Associations of sexhormone-binding globulin (SHBG) with non-SHBG-bound levels of testosterone and estradiol in independently living men. Journal of Clinical Endocrinology and Metabolism 200590 157-162. (doi:10.1210/jc.2004-0422)

34 Brand JS, van der Tweel I, Grobbee DE, Emmelot-Vonk MH \& van der Schouw YT. Testosterone, sex hormone-binding globulin and the metabolic syndrome: a systematic review and meta-analysis of observational studies. International Journal of Epidemiology 201140 189-207. (doi:10.1093/ije/dyq158)

35 Dunning AM, Dowsett M, Healey CS, Tee L, Luben RN, Folkerd E, Novik KL, Kelemen L, Ogata S, Pharoah PDP et al. Polymorphisms associated with circulating sex hormone levels in postmenopausal women. Journal of the National Cancer Institute 200496 936-945. (doi:10.1093/jnci/djh167)

36 Vikan T, Schirmer H, Njølstad I \& Svartberg J. Low testosterone and sex hormone-binding globulin levels and high estradiol levels are independent predictors of type 2 diabetes in men. European Journal of Endocrinology 2010162 747-754. (doi:10.1530/EJE-09-0943)

37 Alemany M. Do the interactions between glucocorticoids and sex hormones regulate the development of the metabolic syndrome? Frontiers in Endocrinology 20123 27. (doi:10.3389/fendo.2012.00027)

38 Pasquali R, Casimirri F, de Iasio R, Mesini P, Boschi S, Chierici R, Flamia R, Biscotti M \& Vicennati V. Insulin regulates testosterone and sex hormone-binding globulin concentrations in adult normal weight and obese men. Journal of Clinical Endocrinology and Metabolism 1995 80 654-658. (doi:10.1210/jc.80.2.654)

39 Vanbillemont G, Lapauw B, de Naeyer H, Roef G, Kaufman JM \& Taes YEC. Sex hormone-binding globulin at the crossroad of body composition, somatotropic axis and insulin/glucose homeostasis in young healthy men. Clinical Endocrinology 201276 111-118. (doi:10.1111/j.1365-2265.2011.04155.x)

40 Hackbarth JS, Hoyne JB, Grebe SK \& Singh RJ. Accuracy of calculated free testosterone differs between equations and depends on gender and SHBG concentration. Steroids 201176 48-55. (doi:10.1016/j. steroids.2010.08.008)

41 Kweon SS, Shin MH, Nam HS, Jeong SK, Park KS, Choi JS \& Lee YH. Sex differences in the associations of testosterone and sex hormonebinding globulin with metabolic syndrome in middle-aged and elderly Koreans - The Namwon Study. Circulation Journal 201377 734-740. (doi:10.1253/circj.CJ-12-0613)

42 Kupelian V, Page ST, Araujo AB, Travison TG, Bremner WJ \& McKinlay JB. Low sex hormone-binding globulin, total testosterone, and symptomatic androgen deficiency are associated with development of the metabolic syndrome in nonobese men. Journal of Clinical Endocrinology and Metabolism 200691 843-850. (doi:10.1210/ jc. 2005-1326)

43 Bhasin S, Jasjua GK, Pencina M, d'Agostino R, Coviello AD, Vasan RS \& Travison TG. Sex hormone-binding globulin, but not testosterone, is associated prospectively and independently with incident metabolic syndrome in men The Framingham Heart Study. Diabetes Care 201134 2464-2470. (doi:10.2337/dc11-0888)

44 Muller M, Grobbee DE, den Tonkelaar I, Lamberts SWJ \& van der Schouw YT. Endogenous sex hormones and metabolic syndrome in aging men. Journal of Clinical Endocrinology and Metabolism 200590 2618-2623. (doi:10.1210/jc.2004-1158)

45 Tanabe M, Akehil Y, Nomiyama T, Murakami J \& Yanase T. Total testosterone is the most valuable indicator of metabolic syndrome among various testosterone values in middle-aged Japanese men. Endocrine Journal 201562 123-132. (doi:10.1507/ endocrj.EJ14-0313)
46 Olszanecka A, Kawecka-Jaszcz K \& Czarnecka D. Association of free testosterone and sex hormone binding globulin with metabolic syndrome and subclinical atherosclerosis but not blood pressure in hypertensive perimenopausal women. Archives of Medical Science 2016 12 521-528. (doi:10.5114/aoms.2016.59925)

47 Gallagher EJ, LeRoith D \& Karnieli E. The metabolic syndrome from insulin resistance to obesity and diabetes. Endocrinology and Metabolism Clinics of North America 200837 559-579. (doi:10.1016/j. ecl.2008.05.002)

48 Alemany M. Metabolic syndrome: a multifaceted disease of affluence. Journal of Endocrinology and Metabolism 20122 155-165. (doi:10.4021/ jem116w)

49 Abraham SB, Rubino D, Sinaii N, Ramsey S \& Nieman LK. Cortisol, obesity, and the metabolic syndrome:a cross-sectional study of obese subjects and review of the literature. Obesity 201321 E105-E117. (doi:10.1002/oby.20083)

50 Stubbins RE, Najjar K, Holcomb VB, Hong J \& Núñez NP. Oestrogen alters adipocyte biology and protects female mice from adipocyte inflammation and insulin resistance. Diabetes Obesity and Metabolism 201214 58-66. (doi:10.1111/j.1463-1326.2011.01488.x)

51 Fernández-Real JM, Ricart W \& Casamitjana R. Lower cortisol levels after oral glucose in subjects with insulin resistance and abdominal obesity. Clinical Endocrinology 199747 583-588. (doi:10.1046/j.13652265.1997.3351120.x)

52 Romero MM, Holmgren-Holm F, Grasa MM, Esteve M, Remesar X, Fernández-López JA \& Alemany M. Modulation in Wistar rats of blood corticosterone compartmentation by sex and a cafeteria diet. PLoS One 20138 e57342. (doi:10.1371/journal.pone.0057342)

53 Hryb DJ, Khan MS, Romas NA \& Rosner W. The control of the interaction of sex hormone-binding globulin with its receptor by steroid-hormones. Journal of Biological Chemistry 1990265 6048-6054.

54 Terasaki T, Nowlin DM \& Pardridge WM. Differential binding of testosterone and estradiol to isoforms of sex hormone-binding globulin: selective alteration of estradiol binding in cirrhosis. Journal of Clinical Endocrinology and Metabolism 198867 639-643. (doi:10.1210/jcem-67-4-639)

55 de Leo V, Musaccio MC, Cappelli V, Massaro MG, Morgante G \& Petraglia F. Genetic, hormonal and metabolic aspects of PCOS: an update. Reproductive Biology and Endocrinology 20161438. (doi:10.1186/s12958-016-0173-x)

56 Sui L-M, Hughes W, Hoppe AJ \& Pétra PH. Direct evidence for the localization of the steroid-binding site of the plasma sex steroidbinding protein (SBP or SHBG) at the interface between the subunits. Protein Science 19965 2514-2520. (doi:10.1002/pro.5560051214)

57 Quental Callou de Sá E, Carleial Feijo de Sá F, Oliveira KC, Feres F $\&$ Nascimento Verreschi IT. Association between sex hormonebinding globulin (SHBG) and metabolic syndrome among men. Sao Paulo Medical Journal 2014132 111-115. (doi:10.1590/15163180.2014.1322666)

58 Chin KY, Ima-Nirwana S, Mohamed IN, Aminuddin A \& Ngah WZW. Total testosterone and sex hormone-binding globulin are significantly associated with metabolic syndrome in middle-aged and elderly men. Experimental and Clinical Endocrinology and Diabetes 2013121 407-412. (doi:10.1055/s-0033-1345164)

59 Rosner W. Free estradiol and sex hormone-binding globulin. Steroids 201599 113-116. (doi:10.1016/j.steroids.2014.08.005)

60 Ornstrup MJ, Kjaer TN, Harslof T, Stodkilde-Jorgensen H, Hougaard DM, Cohen A, Pedersen SB \& Langdahi BL. Adipose tissue, estradiol levels, and bone health in obese men with metabolic syndrome. European Journal of Endocrinology 2015172 205-216. (doi:10.1530/EJE-14-0792)

61 Mauvais-Jarvis F, Clegg DJ \& Hevener AL. The role of estrogens in control of energy balance and glucose homeostasis. Endocrine Reviews 201334 309-338. (doi:10.1210/er.2012-1055) 
62 Schulster M, Bernie AM \& Ramasamy R. The role of estradiol in male reproductive function. Asian Journal of Andrology 201618 435-440. (doi:10.4103/1008-682X.173932)

63 Caldwell JD \& Jirikowski GJ. An active role for steroid-binding globulins: an update. Hormone and Metabolic Research 201345 477-484. (doi:10.1055/s-0033-1334945)

64 Brand JS, Rovers MM, Yeap BB, Schneider HJ, Tuomainen TP, Haring R, Corona G, Onat A, Maggio M, Bouchard C et al. Testosterone, sex hormone-binding globulin and the metabolic syndrome in men: an individual participant data meta-analysis of observational studies. PLoS One 20149 e100409. (doi:10.1371/journal.pone.0100409)

65 Chubb SAP, Hyde Z, Almeida OP, Flicker L, Norman PE, Jamrozik K, Hankey GJ \& Yeap BB. Lower sex hormone-binding globulin is more strongly associated with metabolic syndrome than lower total testosterone in older men: the Health in Men Study. European Journal of Endocrinology 2008158 785-792. (doi:10.1530/EJE-07-0893)

66 Gardill BR, Vogl MR, Lin H-Y, Hammond GL \& Muller YA. Corticosteroid-binding globulin: structure-function implications from species differences. PLoS One 20127 e52759. (doi:10.1371/journal. pone.0052759)

67 Hong D, Kim YS, Son ES, Kim KN, Kim BT, Lee DJ \& Kim KM. Total testosterone and sex hormone-binding globulin are associated with metabolic syndrome independent of age and body mass index in Korean men. Maturitas 201374 148-153. (doi:10.1016/j.maturitas.2012.10.016)

68 Rao PM, Kelly DM \& Jones TH. Testosterone and insulin resistance in the metabolic syndrome and T2DM in men. Nature Reviews Endocrinology 20139 479-493. (doi:10.1038/nrendo.2013.122)

69 Grosman H, Rosales M, Fabre B, Nolazco C, Mazza O, Berg G \& Mesch V. Association between testosterone levels and the metabolic syndrome in adult men. Aging Male 201417 161-165. (doi:10.3109/1 $3685538.2014 .913561)$
70 Kelly DM \& Jones TH. Testosterone and obesity. Obesity Reviews 2015 16 581-606. (doi:10.1111/obr.12282)

71 Kawada T, Otsuka T, Endo T \& Kon Y. Prevalence of the metabolic syndrome and its relationship with diabetes mellitus by aging. Aging Male 201114 203-206. (doi:10.3109/13685538.2011.565092)

72 Hebebrand J \& Bulik CM. Critical appraisal of the provisional DSM-5 criteria for anorexia nervosa and an alternative proposal. International Journal of Eating Disorders 201144 665-678. (doi:10.1002/eat.20875)

73 Onat A, Can G, Çakir H, Özpamuk-Karadeniz F, Karadeniz Y, Yüksel H, Simsek B \& Sdemoglu E. Sex-specific predictors of metabolic syndrome independent of its components. Journal of Investigative Medicine 201563 796-801. (doi:10.1097/JIM.0000000000000203)

74 Chakrabarti S, Lekontseva O \& Davidge ST. Estrogen is a modulator of vascular inflammation. IUBMB Life 200860 376-382. (doi:10.1002/ iub.48)

75 Srinivas-Shankar U, Roberts SA, Connolly MJ, O'Connell MDL, Adams JE, Oldham JA \& Wu FCW. Effects of testosterone on muscle strength, physical function, body composition, and quality of life in intermediate-frail and frail elderly men: a randomized, doubleblind, placebo-controlled study. Journal of Clinical Endocrinology and Metabolism 201095 639-650. (doi:10.1210/jc.2009-1251)

76 Wu IC, Lin XZ, Liu PF, Tsai WL \& Shiesh SC. Low serum testosterone and frailty in older men and women. Maturitas $201067348-352$. (doi:10.1016/j.maturitas.2010.07.010)

77 Griggs RC, Kingston W, Jozefowicz RF, Herr BE, Forbes G \& Halliday D. Effect of testosterone on muscle mass and muscle protein synthesis. Journal of Applied Physiology 198966 498-503.

78 Alexandersen P \& Christiansen C. The aging male: testosterone deficiency and testosterone replacement. An up-date. Atherosclerosis 2004173 157-169. (doi:10.1016/S0021-9150(03)00242-9)

Received 5 October 2016

Revised version received 30 November 2016

Accepted 10 January 2017 